\title{
Is an 87-Year-Old Grandfather Too Marginal for Being a Kidney Donor? The View of Anesthesiologists
}

\author{
Elvin Kesimci ${ }^{a}$, Ezgi Erkilic ${ }^{\text {a }}$, Ibrahim Kilinc $^{\mathrm{b}}$, Mehmet Kilic ${ }^{\mathrm{c}}$
}

\begin{abstract}
Living kidney donation has been accepted increasingly as a result of growth in the number of end-stage renal disease patients awaiting organ. In this aspect using grafts from marginal donors such as with advanced age is increasing in worldwide practice and also in Turkey. Therefore, anesthetic management of donors is particularly important. We herein report the anesthetic management of an 87-year-old grandfather donating his kidney to her granddaughter and review the current anesthetic strategies in a geriatric patient.
\end{abstract}

Keywords: Kidney; Transplantation; Elderly donor; Geriatrics; Anesthesia

\section{Introduction}

In the last decades, the limits on donor organ acceptability have been significantly expanded in worldwide practice. The organ shortage due to the lack of cadaver kidneys and increasing number of transplant recipients, also in Turkey, have promoted living donor kidney transplantation (LDKT). Thus, it has been accepted as a choice of therapy for patients with end-stage kidney disease, since 1975, in our country, but living donors have been used to be family members, commonly parents, in contrast to Europe and United States [1]. As a result, the median age of donors is increasing. However, there are contradictory results about the medical outcomes of living kidney donors [2-4]. Besides, elderly donors, often presenting with several comorbidities, are challenges in perioperative management for

Manuscript accepted for publication July 01, 2016

${ }^{a}$ Anesthesiology and Reanimation Department, Ataturk Training and Research Hospital, Ankara, Turkey

${ }^{b}$ General Surgery Department, Ataturk Training and Research Hospital, Ankara, Turkey

${ }^{\mathrm{c}}$ General Surgery Department, Faculty of Medicine, University of Yildirim Beyazit, Ankara, Turkey

${ }^{\mathrm{d} C o r r e s p o n d i n g ~ A u t h o r: ~ E z g i ~ E r k i l i c, ~ A n e s t h e s i o l o g y ~ a n d ~ R e a n i m a t i o n ~ D e-~}$ partment, Ataturk Training and Research Hospital, Ankara, Turkey.

Email: elvinku@yahoo.com

doi: http://dx.doi.org/10.14740/jocmr2629w anesthesiologists and deserve methiculous care as recipients.

We, herein, present a case of an 87-year-old grandfather donating his kidney to his 24-year-old granddaughter and review current outlines of anesthetic management for geriatric donors.

\section{Case Report}

A 24-year-old female with a body mass index (BMI) of 18.2 $\mathrm{kg} / \mathrm{m}^{2}$ was scheduled for renal transplantation because of atrophic kidneys diagnosed 2 years ago. She did not have dialysis. In her past history, she had an operation of congenital hip dislocation at 2 years of age. At her preanesthetic visit, her physical examination was normal. Among the laboratory parameters, serum creatinine $(5.1 \mathrm{mg} / \mathrm{dL})$ and blood urea nitrogen $(B U N)(131 \mathrm{mg} / \mathrm{dL})$ were remarkable.

Her grandfather was 87 years old, with a BMI of $23.1 \mathrm{~kg} /$ $\mathrm{m}^{2}$. His past medical history revealed no ischemic heart disease, diabetes mellitus, or arterial hypertension. He was neither smoker nor alcoholic. He had a previous anesthetic exposure due to surgical inguinal hernia repair 20 years ago. He was cooperative, oriented and able to perform his routine daily activities without help. He had normal physical examination and laboratory findings. He was thoroughly evaluated including echocardiography, coronary angiography, and abdominalpelvic computed tomography. He was informed about the risks and complications of LDKT. So, as the only suitable donor for the granddaughter, our institute's transplantation committee approved the procedure. Both the donor and the recipient gave written informed consent.

In the operating room, the unpremedicated donor wearing graduated stockings was monitored with electrocardiography, non-invasive arterial blood pressure (BP), arterial oxygen saturation $\left(\mathrm{SpO}_{2}\right)$, capnography, body temperature and urine output. Following pre-oxygenation with $100 \%$ oxygen for $3 \mathrm{~min}$, anesthesia was induced with $3 \mathrm{mg} / \mathrm{kg}$ intravenous thiopentone and a continuous infusion of remifentanil $(0.1-0.15 \mu \mathrm{g} / \mathrm{kg} /$ $\mathrm{min}$ ). Lidocaine $1 \mathrm{mg} / \mathrm{kg}$ and rocuronium $0.6 \mathrm{mg} / \mathrm{kg}$ were administered to attenuate the response to laryngoscopy and intubation and to facilitate the endotracheal intubation, respectively. Then, a large bore intravenous catheter was inserted into the right external jugular vein. Thus, the patient was positioned in lateral decubitus for a flank incision. He was given 5,000 $\mathrm{U}$ heparin for prophylactic purposes. For maintenance of anesthesia, sevoflurane was titrated to have a minimal alveolar 
concentration (MAC) of 1.5-2 with 50\% oxygen in air mixture together with remifentanil infusion. Intraoperative fluid was administered according to hemodynamic status, to keep intraoperative blood pressure and heart rate in the limits at or above the preoperative values and an adequate urine output of greater than $100 \mathrm{~mL} / \mathrm{h}$ following loading fluid. All intravenous fluids were warmed. Before nephrectomy, mannitol $0.5 \mathrm{~g} / \mathrm{kg}$ was administered. After removal of the right kidney, $50 \mathrm{mg}$ protamine was administered. The surgery lasted 152 min. During this time, the recipient was prepared in the neigbor operating room. The warm ischemia time was $45 \mathrm{~min}$. At the end of the surgery, for surgical site analgesia, we used $20 \mathrm{~mL} 0.25 \%$ bupivacaine infiltration. Sevoflurane and remifentanil were discontinued, and the neuromuscular block was reversed with sugammadex and he was extubated. He was taken to the post-anesthesia care unit (PACU), for further follow-up and pain relief. Intravenous fentanyl patient controlled analgesia (PCA) pump was used in PACU (fentanyl $1.5 \mu \mathrm{g} / \mathrm{kg}$ loading dose, a bolus dose of $25 \mu \mathrm{g}$, with a lock-out time of $10 \mathrm{~min}$, and $400 \mu \mathrm{g}$ total infusion dose with a 4-h limitation). During the postoperative course, he had no problems related to anesthesia or pain. He was discharged on the sixth postoperative day without any problem. At his controls, at postoperative first to second month, there was neither complaints nor abnormal laboratory findings.

\section{Discussion}

The discrepancy between demand and supply in kidney transplantation and the resulting increase in wait-list have forced transplant centers to expand their limits on donor's characteristics, including age [5-8]. Despite the progress in the follow-up of recipients, the exact long-term outcomes after donation in marginal donors are lacking or controversial [3, 4, 9]. Yet, the role of anesthesiologists is challenging for perioperative management of a marginal donor.

Geriatric patients are considered to have a higher risk for surgery. Although advanced age is not a contraindication for surgery, these patients deserve attention due to decline in organsystem functions and frailty caused by co-morbidities [10].

The management of the kidneys under anesthesia during transplantation is one of the most important responsibilities of the anesthesiologist. Commonly, the advanced age of the patient is not enough to interpret about the function and viability of nephrons [11]. Terasaki et al reported an increase in delayed graft function, serum creatinine level and need for dialysis postoperatively in recipients transplanted from elderly donors [12]. On the other hand, the risk of living kidney donation is not reported to be high in healthy individuals [13]. The ages of both donor and recipient are blamed to influence transplant outcomes [14]. Some authors suggest routine kidney biopsy from elderly donors before having transplantation decision [15]. However, we did not have pretransplant biopsy likewise some other authors disagreeing this idea [16]. Ojo et al showed a relative risk of graft loss $>1.7$ in suboptimal transplants when compared to optimal ones [17]. In another study, in comparison to cadaver donors, elderly living donors were found to be significantly better than young cadaver donors [18]. Although some authors report the association of success of the transplant with donor characteristics and organ quality, the findings of studies are conflicting [14]. Probably, the age of the recipients is also important, even if the transplanted kidney is older, since lesions in a diseased kidney reverse after transplantation with a functional graft survival [19-21]. Our recipient was a young lady, and the transplanted kidney was fortunately healthy.

After induction, we had a large bore intravenous access instead of invasive monitorization for the donor. We usually have invasive arterial and central venous pressure monitorization in the elderly with co-morbidities, undergoing major surgery. Nevertheless, the donor did not complain of any systemic diseases, but as a prevention against probable major bleeding, having large bore intravenous access was thought sufficient.

In this type of surgeries, the geriatric donor has a high risk of developing venous thromembolism, thus we provided him with graduated stockings, and heparin before application of arterial clamp intraoperatively. As a result of this, we did not prefer regional anesthesia and analgesia in this patient. The patient had lateral decubitus position for more than $2 \mathrm{~h}$. Thus, we checked the paddings regularly as to prevent the nerve injuries and stress ulcers.

In these patients, open surgeries are particularly painful. For postoperative pain control, we used $20 \mathrm{~mL} 0.25 \%$ bupivacaine infiltration for surgical site analgesia and intravenous fentanyl PCA pump. On the first postoperative day, he was mobilized without any pain. We tried to hydrate the patient well and avoid any non-steroidal antiinflammatory drugs in the next days. By substantial progress in renal transplant surgery, laparoscopic donor nephrectomy has been preferred for a number of advantages to open surgery, by most centers [22]. It would probably be a very judicious choice for this geriatric patient; however, our surgical team did not prefer this technique in this aspect.

In the postoperative period, donors are usually faced with transient complications like microalbuminuria or increase in serum creatinine [23]. In this patient, there was a slight increase in serum creatinine levels. However, the increased blood pressure was remarkable on the first postoperative day. Thus, we ordered a calcium channel blocker to him. By this medication, his blood pressure measurement returned to normal in the next 5 days. This could be contributed probably to his advanced age. There are no reports showing the association between unilateral nephrectomy and the risk of hypertension [23]. Choi et al suggested the importance of follow-up of donors in the first year, as adverse effects could be seen even in patients with normal preoperative renal function [24].

In Turkey, the use of elderly living donor kidneys is increasing nowadays, because more than 20,000 patients await a suitable organ [25]. This situation makes particularly anesthesiologists to concentrate on the issues like safety, preservation and optimization of donors as well as recipients. The present case aimed to report a succesful anesthetic management of a geriatric patient in the light of renal transplantation.

\section{References}

1. Haberal M, Sert S, Aybasti N, Gulay H, Gokce O, Arslan G, Karamehmetoglu M, et al. Living donor kidney trans- 
plantation. Transplant Proc. 1988;20(1 Suppl 1):353-355.

2. Ommen ES, Winston JA, Murphy B. Medical risks in living kidney donors: absence of proof is not proof of absence. Clin J Am Soc Nephrol. 2006;1(4):885-895.

3. Ibrahim HN, Foley R, Tan L, Rogers T, Bailey RF, Guo $\mathrm{H}$, Gross CR, et al. Long-term consequences of kidney donation. N Engl J Med. 2009;360(5):459-469.

4. Gossmann J, Wilhelm A, Kachel HG, Jordan J, Sann U, Geiger H, Kramer W, et al. Long-term consequences of live kidney donation follow-up in $93 \%$ of living kidney donors in a single transplant center. Am J Transplant. 2005;5(10):2417-2424.

5. Wolfe RA, Ashby VB, Milford EL, Ojo AO, Ettenger RE, Agodoa LY, Held PJ, et al. Comparison of mortality in all patients on dialysis, patients on dialysis awaiting transplantation, and recipients of a first cadaveric transplant. $\mathrm{N}$ Engl J Med. 1999;341(23):1725-1730.

6. Cohen B, Persijn GG. Trends in organ donation. Transplant Proc. 1997;29(8):3301-3302.

7. Spital A. Ethical and policy issues in altruistic living and cadaveric organ donation. Clin Transplant. 1997;11(2):7787.

8. Molnar MZ, Streja E, Kovesdy CP, Shah A, Huang E, Bunnapradist S, Krishnan M, et al. Age and the associations of living donor and expanded criteria donor kidneys with kidney transplant outcomes. Am J Kidney Dis. 2012;59(6):841-848.

9. Li Y, Li J, Fu Q, Chen L, Fei J, Deng S, Qiu J, et al. Kidney transplantation from living related donors aged more than 60 years: a single center experience. Ren Fail. 2013;35(9):1251-1254.

10. Sullivan LM, Massaro JM, D'Agostino RB, Sr. Presentation of multivariate data for clinical use: The Framingham Study risk score functions. Stat Med. 2004;23(10):16311660 .

11. Hubbard WJ, Dashti N. Aging and transplantation - a topic for biomedicine or bioethics? Aging Dis. 2011;2(2):181185.

12. Terasaki PI, Gjertson DW, Cecka JM, Takemoto S, Cho YW. Significance of the donor age effect on kidney transplants. Clin Transplant. 1997;11(5 Pt 1):366-372.

13. Narkun-Burgess DM, Nolan CR, Norman JE, Page WF, Miller PL, Meyer TW. Forty-five year follow-up after uninephrectomy. Kidney Int. 1993;43(5):1110-1115.

14. Veroux M, Grosso G, Corona D, Mistretta A, Giaquinta A, Giuffrida G, Sinagra N, et al. Age is an important predictor of kidney transplantation outcome. Nephrol Dial Transplant. 2012;27(4):1663-1671.

15. Remuzzi G, Cravedi P, Perna A, Dimitrov BD, Turturro M, Locatelli G, Rigotti P, et al. Long-term outcome of renal transplantation from older donors. $\mathrm{N}$ Engl J Med. 2006;354(4):343-352.

16. Karatzas T, Bokos J, Katsargyris A, Diles K, Sotirchos G, Barlas A, Theodoropoulou E, et al. Advanced donor age alone is not a risk factor for graft survival in kidney transplantation. Transplant Proc. 2011;43(5):1537-1543.

17. Ojo AO, Hanson JA, Meier-Kriesche H, Okechukwu CN, Wolfe RA, Leichtman AB, Agodoa LY, et al. Survival in recipients of marginal cadaveric donor kidneys compared with other recipients and wait-listed transplant candidates. J Am Soc Nephrol. 2001;12(3):589-597.

18. Kerr SR, Gillingham KJ, Johnson EM, Matas AJ. Living donors $>55$ years: to use or not to use? Transplantation. 1999;67(7):999-1004.

19. Pessione F, Cohen S, Durand D, Hourmant M, Kessler M, Legendre C, Mourad G, et al. Multivariate analysis of donor risk factors for graft survival in kidney transplantation. Transplantation. 2003;75(3):361-367.

20. Gomez E, Aguado S, Tejada F, Diaz-Corte C, Seco M, Alvarez-Grande J. Successful transplant of kidneys with diffuse diabetic glomerulosclerosis. Transplantation. 1995;59(1):156.

21. Rea R, Smith C, Sandhu K, Kwan J, Tomson C. Successful transplant of a kidney with focal segmental glomerulosclerosis. Nephrol Dial Transplant. 2001;16(2):416-417.

22. Kadam P, Butala B, Shah V. Anesthetic management of laparoscopic dual renal transplantation. Saudi J Kidney Dis Transpl. 2014;25(5):1051-1055.

23. Hartmann A, Fauchald P, Westlie L, Brekke IB, Holdaas H. The risk of living kidney donation. Nephrol Dial Transplant. 2003;18(5):871-873.

24. Choi KH, Yang SC, Joo DJ, Kim MS, Kim YS, Kim SI, Han WK. Clinical assessment of renal function stabilization after living donor nephrectomy. Transplant Proc. 2012;44(10):2906-2909.

25. Turkish Society of Nephrology Registry Data, 2012. 